\title{
A DIMENSÃO AMBIENTAL NA URBANIZAÇÃO DE FAVELAS: VISÃO CRÍTICA SOBRE DRENAGEM NOS ESTUDOS DE CASO DAS BACIAS DO PONTE BAIXA E SAPÉ, SÃO PAULO
}

\section{THE ENVIRONMENTAL DIMENSION IN SLUM UPGRADING: A CRITICAL VIEW ON DRAINAGE IN THE CASE STUDIES OF PONTE BAIXA AND SAPÉ BASINS, SÃO PAULO}

\begin{abstract}
Ellen Emerich Carulli( ${ }^{(1)}$
Engenheira Ambiental Urbana, Mestranda em Planejamento e Gestão do Território - Universidade Federal do ABC. Luciana Nicolau Ferrara ${ }^{(2)}$

Arquiteta e Urbanista, Docente na Universidade Federal do ABC.

Érica Cristina Medeiros Machado ${ }^{(3)}$

Engenheira Civil, Docente na Universidade Federal de Campina Grande, pós-doutoranda na Universidade Federal do ABC.

Melissa Cristina Pereira Graciosa ${ }^{(4)}$

Engenheira Civil, Docente na Universidade Federal do ABC.

E-mail ${ }^{(1)}$ : emerich.carulli@gmail.com

\section{RESUMO}

Este artigo apresenta os principais resultados da análise crítica de dois projetos do Programa de Aceleração do Crescimento (PAC), no município de São Paulo, que confrontam as soluções de drenagem e sua interface com favelas, com enfoque sobre seus impactos sociais e ambientais. A abordagem do projeto PAC-Drenagem da sub-bacia do Córrego Ponte Baixa e Jardim Letícia associa drenagem à solução viária com remoção de diversas favelas. Já o projeto PACUrbanização da favela do Sapé implantou como solução canalização e parque linear. As investigações indicam para uma priorização do sistema viário sobre o hídrico e soluções de drenagem que tratam as cheias do ponto de vista do transporte, e não do amortecimento. Notou-se como resultados a fragmentação das soluções, a baixa interrelação entre soluções de urbanismo e paisagismo e a pouca participação social, o que, consequentemente, resulta em uma abordagem menos abrangente da dimensão ambiental nos projetos.
\end{abstract}

\begin{abstract}
This article aims to present the main results of acritical analysis of two projects of the Growth Acceleration Program (PAC), in the city of São Paulo, which confront drainage solutions and their interface with slums focusing on the social and environmental approach. The PAC-Drainage project in the Ponte Baixa and Jardim Letícia sub-basins combines drainage with the road solution associated with the removal of several slums. The PAC-Urbanization project in the Sapé slum implemented a channel and linear park as drainage solution. Investigations point to prioritizing the road system over water and drainage solutions that address flooding from the point of view of transport rather than reservation. The research points to the fragmentation of solutions, the low interrelationship between urban planning and landscaping solutions and a poor social participation, which, consequently, results in a less specific and local approach to the environmental dimension in the projects.
\end{abstract}

Palavras-chave: Urbanização de favelas, Drenagem urbana, Qualificação urbanística-ambiental

Key words: Slum upgrading, Urban drainage, Urban and environmental quality

\section{INTRODUÇÃ̃O}

Este artigo apresenta os principais resultados da pesquisa em rede "A dimensão ambiental e as infraestruturas na urbanização de favelas: concepções de projetos, formas de produção das redes e 
especificidades dos assentamentos precários", no que tange aos estudos de caso do município de São Paulo. O trabalho enfatiza a relação entre urbanização de favelas, corpos d'água e moradia. Tal relação se traduz no descompasso entre a necessidade do acesso à terra urbanizada pela população de baixa renda e a consequente ocupação de áreas ambientalmente protegidas ou impróprias à edificação, considerando, além disso, a distribuição desigual das infraestruturas no espaço urbano. No momento da urbanização da favela, esta relação se desdobra em decisões técnicas, econômicas e políticas para intervir nos corpos d'água a partir de conhecimentos e práticas de engenharia adotadas, em geral, e nos assentamentos precários, em particular.

De acordo com Ferrara et al. (2019), para além da qualificação da moradia, as intervenções de infraestrutura na urbanização de favelas devem melhorar o assentamento do ponto de vista urbano e ambiental. No entanto, as especificidades do padrão da ocupação precária demandam soluções técnicas específicas de acordo com cada caso. Atender a tais especificidades não é algo consueto, visto que, a depender das soluções adotadas, outros conflitos e impactos podem ser gerados, especialmente porque as intervenções recentes e de grande porte têm implicado em um número elevado de remoção de moradias (CARDOSO; DENALDI, 2018), o que demanda maiores investimentos para aquisição de terreno, construções e assistência social das famílias.

As favelas em áreas urbanas concentram os déficits de saneamento, conforme aponta o Panorama do Saneamento Básico no Brasil (MINISTÉRIO DAS CIDADES, 2014). O esgotamento sanitário e a drenagem urbana estão em pior situação quando comparados com os indicadores de abastecimento de água, limpeza urbana e manejo dos resíduos sólidos. A qualidade e a oferta das infraestruturas de esgoto e de drenagem afetam as áreas urbanas como um todo e estão relacionadas às características sociais e geográficas de ocupação das bacias hidrográficas, mas os impactos sociais e econômicos são mais significativos nas favelas. As soluções para essas redes refletem práticas dos prestadores de serviços orientadas por racionalidades econômicas que nem sempre respondem às necessidades sociais. Ressalta-se, também, o predomínio de soluções técnicas tradicionais, tecnicistas, higienistas e baseadas em aumento dos volumes e picos de escoamento superficial. Já os princípios orientados pela Drenagem Moderna baseados na reservação aliados a medidas não estruturais (TUCCI; PORTO; BARROS, 1995; CANHOLI, 2014), embora em avanço, ainda são pouco ou nada aplicados nos casos de urbanização de favelas.

Em São Paulo, a maior parte das favelas se localiza em fundos de vale ou margens de corpos d'água, áreas suscetíveis à inundação, o que torna a drenagem urbana fundamental nas urbanizações de favelas. Além de funcionar como parte das infraestruturas de saneamento, a drenagem é necessária ao controle de cheias, à mitigação de áreas de risco, à melhoria da saúde pública e pode ser combinada à possibilidade de criação de espaços coletivos. Contudo, para a população, em geral, a relação com os córregos não é positiva, justamente porque apresentam poluição, mau cheiro, insetos e outros vetores de doenças, tornando esses espaços ainda mais distantes de lugares desejados de apropriação e convivência.

Considerando esse contexto, a pesquisa analisou dois projetos com objetivos distintos, nos quais a drenagem foi elemento estruturante da intervenção, confrontando diferentes soluções e interfaces com favelas. Esses projetos foram realizados no âmbito do Programa de Aceleração do Crescimento (PAC) no município de São Paulo: o PAC Urbanização de Assentamentos Precários (PAC-UAP) Favela do Sapé, na zona sul de São Paulo, e o PAC Prevenção de Áreas de Risco (PAC-PAR) em que se insere a ação PAC-Drenagem ${ }^{1}$ na bacia do córrego Ponte Baixa e Jardim Letícia, zona oeste de São Paulo.

\footnotetext{
${ }^{1}$ No programa "Prevenção de Áreas de Risco", embora não haja uma linha específica denominada PAC-Drenagem, o termo "drenagem" tem sido adotado pelas prefeituras nos projetos que receberam recursos do PAC. Na modalidade PAC-
} 
O primeiro projeto, denominado PAC-Drenagem da bacia do córrego Ponte Baixa e do Jardim Letícia, consiste na intervenção viária e em ações de macrodrenagem que afetaram diversas favelas, removendo-as integralmente. Já o segundo, realizado no âmbito do PAC-UAP, são intervenções para urbanizar a favela do Sapé e o córrego adjacente. Além das concepções técnicas de drenagem e de sua relação com a execução dos projetos, é essencial destacar que a problemática das águas em assentamentos urbanos precários é complexa e abrange aspectos sociais, econômicos, políticos e ambientais, envolvendo desde a reivindicação de moradores por urbanização e pelo direito à cidade, água e moradia, passando pelas políticas públicas e habitacionais e desenho dos financiamentos e condicionantes legais dos programas de urbanização, até a participação social nos processos decisórios.

Apesar dessa reconhecida multidimensionalidade, as reflexões sobre os estudos de caso apontam as principais contribuições levantadas sobre os avanços, potencialidades e dificuldades do tratamento da drenagem na urbanização de favelas. Além disso, os projetos permitem interpretar como essa infraestrutura representa um caminho para a compreensão da dimensão ambiental nos assentamentos precários.

As questões de referência no estudo foram: apesar de as obras terem pontos de partida com objetivos diferentes, as concepções de projeto de drenagem foram semelhantes? Quais foram os resultados quanto à solução da drenagem? Como se deram as interfaces com a solução habitacional e qualificação ambiental da localidade e microbacia em que estão inseridos os projetos? Embora esta análise privilegie a dimensão projetual e técnica, ao mesmo tempo, tais projetos fornecem elementos para uma reflexão crítica sobre a forma como a dimensão ambiental tem sido incorporada aos planos de urbanização de favelas. Assim, também evidencia contradições, conflitos e potencialidades dessas intervenções.

\section{METODOLOGIA}

A análise dos projetos de intervenção foi realizada em dois momentos, que se relacionam e se complementam. A primeira foi uma leitura socioterritorial das bacias hidrográficas onde estão localizadas as áreas dos projetos e, a segunda, pautou-se em uma leitura das concepções de projeto. A seguir são apresentadas, em resumo, as metodologias dessas etapas para, depois, serem apresentados os resultados e debates gerados a partir de cada uma delas.

As bacias de estudo de caso - do córrego Ponte Baixa e do Sapé - foram analisadas a partir de um diagnóstico integrado urbano e ambiental que contemplou a leitura socioterritorial, com objetivo de contextualizar a área da intervenção quanto ao seu entorno, incorporando aspectos fisiográficos, urbanos e socioeconômicos, a partir de dados do IBGE, Geosampa, Habitasampa e Fundação Seade. A caracterização da dimensão da drenagem contextualizou a bacia hidrográfica por meio da leitura das condicionantes hidrológicas e hidráulicas, características morfométricas e histórico de ocorrências de alagamentos e inundações, contemplando tanto os aspectos físicos e bióticos quanto às alterações na bacia por atividades antrópicas da urbanização. As condições de vulnerabilidade social estão incluídas nas condicionantes gerais de drenagem, pois se relacionam com a suscetibilidade e a exposição ao risco de inundações e alagamentos.

A análise crítica de concepção dos projetos compôs parcela relevante do trabalho, com objetivo de sistematizar de que maneira o escopo dos projetos de drenagem e infraestrutura urbana se constroem nas propostas de urbanização de favelas e como lidam com as questões de moradia precária. Como método, adotou-se entrevistas realizadas com atores-chave nos projetos (gestores públicos, técnicos

PAR nem sempre os projetos incidiram sobre áreas de favelas, diferente do PAC-UAP cujo objetivo era a urbanização integrada. 
da área de infraestrutura, urbanismo, assistência social e projetistas), considerando suas distintas formações, ocupações e visões sobre a temática de infraestrutura e saneamento em urbanização de favelas, além da avaliação crítica dos projetos a partir de análise documental. Também foram utilizadas as abordagens modernas da drenagem mencionadas como referências teóricas.

A análise documental foi sistematizada em seis grandes componentes: (i) informações gerais da área de estudo (bacia hidrográfica e assentamento precário); (ii) dados de contrato, planejamento e execução do projeto; (iii) detalhamento da intervenção de drenagem - tipo, escala e classificação; (iv) aspectos de saneamento, meio ambiente e educação ambiental - ocorrências de inundações e/ou alagamentos, áreas de risco, recuperação e controle de poluição, entre outras ações; (v) urbanização e habitação - remoções, reassentamentos, participação social, requalificação habitacional, ações pósocupacional/pós-intervenção; (vi) alteração de projeto, melhorias, dificuldades e conflitos.

\section{RESULTADOS E DISCUSSÃO}

No município de São Paulo, o PAC-PAR abrangeu, de 2015 a 2018, 12 intervenções com investimentos de R \$1.574.362.771,17 (PAC, 2018). Dez destas intervenções foram associadas diretamente a soluções de drenagem: canalização de córregos, reservatórios de amortecimento, parque linear, galerias de programa de redução de alagamentos. Nesse município, uma característica marcante do PAC-UAP foi a utilização de recursos para viabilizar a urbanização de favelas que já vinham sendo desenvolvidas, tanto pela Secretaria de Habitação (SEHAB) quanto pela Companhia de Desenvolvimento Habitacional e Urbano (CDHU) (AKAISHI; SARAIVA; CARDOSO et al., 2018). Onze intervenções foram realizadas nesta linha, com investimento da ordem de $\mathrm{R} \$$ 2.009.595.668,22 (PAC, 2018).

A intervenção realizada pelo PAC-Drenagem foi desenvolvida pela Secretaria de Infraestrutura e Obras (SIURB) e pela Secretaria Municipal do Verde e do Meio Ambiente (SVMA), que contratou a elaboração do projeto escritório Geométrica e a execução pelo Consórcio Camargo Corrêa - Mendes Júnior. As obras duraram entre 2013 e 2018. Além dos recursos oriundos do PAC-Drenagem (R\$ 2,95 bilhões), o financiamento foi complementado com contrapartidas da Prefeitura de São Paulo (PMSP) (R \$ 1,75 bilhões).

O projeto no córrego Ponte Baixa foi pautado pela demanda de criação de um novo eixo de mobilidade entre a Zona Sul e Centro da cidade, complementar à sobrecarregada Estrada do M'Boi Mirim. Isto resultou na criação de uma nova avenida, a Luiz Guschinken, no espaço antes ocupado por favelas. A priorização do modal rodoviário conduziu à criação de um eixo largo, com várias faixas para veículos, e à restrição do espaço das águas em um canal retificado e revestido de concreto, sem qualquer arborização de margens ou espaços de convivência da cidade com as águas. Muito embora a implantação de um coletor tronco para os esgotos tenha proporcionado melhoria para a qualidade de vida e saúde ambiental, tais efluentes continuam sendo conduzidos, sem o devido tratamento, para o lago da represa Guarapiranga, exutório da bacia. Além disso, o reservatório de retenção de cheias inicialmente previsto, foi retirado do projeto final, sob a alegação de que o canal seria suficiente para conter as cheias, não sendo levada em conta a possibilidade de que, com o amortecimento e, consequentemente, com menores vazões a jusante, poderiam ser consideradas outras tipologias, mais naturais e harmonizadas, do que o canal retificado em concreto. Já a intervenção no Jardim Letícia, consistiu na remoção de assentamentos precários sobre o córrego e implantação de Parque Linear que, por sua vez, não abrangeu a microbacia como um todo.

O projeto de urbanização da Favela do Sapé foi contratado pela SEHAB e a execução das obras foi dividida entre dois consórcios: Sapé A e Sapé B. O consórcio Engelux/Galvão ficou responsável por executar as obras do Sapé A, enquanto as obras do Sapé B foram feitas pelo consórcio ETEMP/Croma. Para ambas as áreas, o projeto urbanístico foi elaborado pela empresa Base Urbana, 
visando integrar as intervenções propostas aos diversos projetos complementares. Os valores licitados para as áreas Sapé A e Sapé B foram, respectivamente, de R\$ 43.352.050,16 e R\$ 34.816.088,36. Porém, ao final das obras, os valores gastos acabaram sendo bem superiores aos planejados, ficando em R \$ 58.060.785,80 e R \$ 52.503.884,75, respectivamente (VENTURA, 2019).

Do ponto de vista da drenagem, a tipologia adotada para o córrego do Sapé considerou a implantação de parque linear como espaço verde de lazer para a população local, e se articulou ao desenho dos novos conjuntos habitacionais. A análise crítica do projeto, neste caso, é de que, embora tenha sido preservada uma faixa arborizada, a tipologia adotada para o canal permaneceu convencional, em sua maior parte em gabião, parte em concreto, retificado. Em alguns trechos, vistorias recentes apontaram para elevado grau de degradação, com presença de lixo e entulho, resultado do descuido com aspectos de zeladoria e manutenção. Destaca-se também a descontinuidade no projeto, em que o parque é interrompido em certo ponto sem qualquer elemento paisagístico ou urbano que promova a sua integração no espaço urbano. A prática de repartição de obras de infraestrutura em lotes pode encontrar amparo em aspectos econômicos e de execução de obras públicas, mas tem-se mostrado prejudicial para a harmonia final e continuidade da intervenção.

\section{CONCLUSÕES}

Os projetos analisados possuem escopos distintos, no entanto, a comparação entre a abordagem da drenagem entre ambos possibilitou destacar como a dimensão ambiental foi tratada nas intervenções em interface com as favelas. Semelhanças e diferenças foram destacadas entre as abordagens dos estudos de caso compreendendo escolha de alternativas, diferenças entre projeto planejado e executado, padrão urbano, discussão sobre ganhos ambientais e importância da participação social.

Em relação ao padrão urbano das intervenções, em ambos os projetos ressalta-se a predominância da convencional ocupação de fundo de vale por estrutura viária, privilegiando o modal individual motorizado, acompanhado de canalização retificada e transferência de cheias para jusante. No entanto, o projeto do Sapé evidencia que, ao associar os elementos de drenagem como parte de um projeto integrado de urbanização, podem ser obtidas melhorias nas condições urbanísticas e de moradia da população, bem como adotadas soluções de tratamento distinto dos corpos d'água, como revestimentos mais permeáveis e a consideração do rio como um elemento da paisagem. Essas qualidades não estão presentes na intervenção do córrego Ponte Baixa.

Em relação à definição de parâmetros para aferir qualidade ambiental, observa-se a sua ausência quando se trata de infraestruturas de saneamento e drenagem. Contudo, observou-se, nos projetos de macrodrenagem, que o ganho ambiental está mensurado pelo tratamento da quantidade de escoamento e redução de inundações e alagamentos. Tal visão acaba por reduzir a concepção da drenagem sob o ponto de vista da quantidades, não sendo abordadas as demais funções como controle de qualidade de tratamento paisagístico, oferta de espaços livres, recarga dos aquíferos, restabelecimento da fauna e flora aquáticas, provimento de áreas de convívio e lazer.

Ao olharmos as intervenções integradas de urbanização de favelas, é possível notar outras percepções de ganho ambiental. Por exemplo, a visão de garantir a proteção ou requalificação da APP, gerando espaços públicos e comunitários, mas sem desconsiderar os impactos causados pelas remoções de moradias e pelo tratamento das áreas de risco, que demandam o equacionamento da solução habitacional quando a remoção é inevitável. Muitas das vezes, a qualificação é percebida quando se trata da drenagem junto a outros aspectos do saneamento ambiental, como esgotamento sanitário e tratamento de resíduos, provocando uma melhoria da qualidade de água do córrego e no ambiente. No entanto, o debate não se restringe às soluções técnicas; as contradições existem entre soluções aplicadas e impactos socioambientais. Nesse sentido, não se pode deixar de mencionar a importância 
da participação social desde a concepção do projeto e da atuação engajada politicamente dos moradores e lideranças locais deve ser ressaltada.

É crucial que o poder público adote novas diretrizes e concepções de projetos que avancem em concepções mais abrangentes da drenagem na urbanização de favelas e na dimensão ambiental das intervenções, bem como se comprometa com a zeladoria dos espaços pós-obra, especialmente em contexto de vulnerabilidade social. A intersetorialidade é um meio para garantir que diversas compreensões sobre projeto e soluções sejam articuladas e integradas. Por outro lado, ela ainda se apresenta como uma agenda e um desafio na urbanização de favelas e para garantir a sua apropriação pelos moradores.

\section{AGRADECIMENTOS}

Essa pesquisa recebeu o apoio do Projeto "As metrópoles e o Direito à Cidade: plataforma de conhecimento, inovação e ação para o desenvolvimento urbano - Programa de Pesquisa da Rede Observatório das Metrópoles 2015-2020”, Chamada INCT - MCTI/CNPq/CAPES/FAPS n 16/2014, subprojeto "Direito à Cidade e Habitação", dentro do Programa Institutos Nacionais de Ciência e Tecnologia (INCT) do CNPq.

\section{REFERÊNCIAS BIBLIOGRÁFICAS}

AKAISHI, A. N.; SARAIVA, C. P.; CARDOSO, L. C.; SILVA, P. C. "O programa de aceleração do crescimento no contexto das urbanizações de favela em São Paulo". In: CARDOSO, A. L; DENALDI, R. (orgs.). Urbanização de favelas no Brasil. Um balanço preliminar do PAC. Rio de Janeiro: Letra Capital, 2018.

CARDOSO, A. L; DENALDI, R. Urbanização de Favelas no Brasil. Um balanço preliminar do PAC. Rio de Janeiro: Letra Capital, 2018.

CANHOLI, A. P. Drenagem Urbana e Controle de Enchentes. 2a edição. São Paulo: Oficina de Textos, 2014.

FERRARA, L. N.; FURIGO, R.; MORETTI, R. S.; SAMORA, P. R. "Saneamento básico e urbanização de favelas: os desafios de universalização à luz das especificidades de ocupação dos assentamentos precários". In: FERREIRA, L.; OLIVEIRA, P.; IACOVINI, V. (orgs). Dimensões do intervir em favelas: desafios e perspectivas. 1ed. São Paulo: Peabiru TCA e Coletivo Lablaje, v. 1, p. 104-111, 2019.

IBGE (Instituto Brasileiro de Geografia e Estatística). Censo 2010. Disponível em https://censo2010.ibge.gov.br/. Acesso em 21 set. 2021.

PAC - PROGRAMA DE ACELERAÇÃO DO CRESCIMENTO. Infraestrutura social e urbana - São Paulo/SP. Data de referência: 30 jun. 2018. Disponível em http://www.pac.gov.br/infraestrutura-social-eurbana/sp, acessado em 1 set. 2021.

MINISTÉRIO DAS CIDADES. Panorama do saneamento básico no Brasil - vol 2.: Análise situacional do déficit em saneamento básico. MORAES, L. R. S. (coord). Brasília: Ministério das Cidades/ Secretaria Nacional de Saneamento Ambiental, 2014. 340 p.

SILVA, J. D. Intervenções nos Córregos da Ponte Baixa e Jardim Letícia - Soluções de Drenagem, Direito à Moradia e Integração Territorial. 2019. 204 p. Dissertação (Mestrado /em Planejamento e Gestão do Território) - Universidade Federal do ABC, São Bernardo do Campo, São Paulo, 2019.

TUCCI, C. E. M; PORTO, R. L. L; BARROS, M. Drenagem Urbana. Porto Alegre: ABRH/ Editora da Universidade/ UFRGS, 1995. 

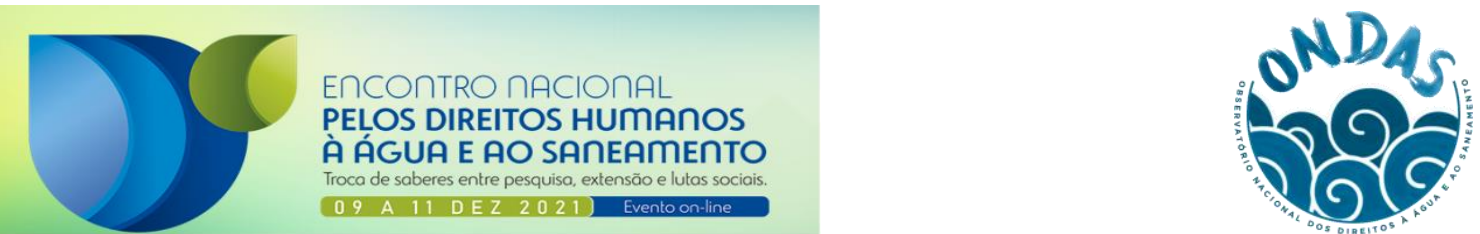

VENTURA, I. Urbanização de favelas: estudo sobre os diferentes tipos de intervenção. 202 p. 2019. Dissertação (Mestrado em Arquitetura e Urbanismo) - Faculdade de Arquitetura e Urbanismo da Universidade de São Paulo, São Paulo, São Paulo, 2019. 